\title{
Correction: ERK3/MAPK6 is required for KRAS-mediated NSCLC tumorigenesis
}

Katarzyna Bogucka (D) Federico Marini - Sebastian Rosigkeit • Janine Schloeder • Helmut Jonuleit • Kerstin David • Margarita Schlackow • Krishnaraj Rajalingam (D)

Published online: 9 November 2020

(c) The Author(s), under exclusive licence to Springer Nature America, Inc. 2020

Correction to: Cancer Gene Therapy

https://doi.org/10.1038/s41417-020-00245-w

published online 17 October 2020
This Article was originally published under an Open Access licence [CC BY 4.0] in error. It should have been published under Nature Research's License to Publish.

The PDF and HTML versions of the Article have been corrected accordingly. 